\title{
Effect of lactulose on growth performance and intestinal morphology of pre-ruminant calves using a milk replacer containing Enterococcus faecium
}

\author{
S. Fleige ${ }^{1}$, W. Preißinger ${ }^{2}$, H. H. D. Meyer ${ }^{1}$ and M. W. Pfaff| ${ }^{1 \dagger}$ \\ ${ }^{1}$ Institute of Physiology, Centre of Life and Food Sciences (ZIEL), Technical University of Munich, 85354 Freising, Germany; ${ }^{2}$ Institut für Tierernährung und \\ Futterwirtschaft, Bayerische Landesanstalt für Landwirtschaft (LfL), 85586 Poing-Grub, Germany
}

(Received 16 May 2006; Accepted 13 November 2006)

\begin{abstract}
The synthetic disaccharide lactulose is known to improve the intestinal microflora by stimulating the growth of selected probiotic bacteria in the gut. In our experiment the effects of lactulose in combination with the probiotic bacteria Enterococcus faecium on growth performance and morphology of the bovine intestine were examined. Calves aged $39 \pm 2$ days were randomised to three feeding groups (no. = 14 each group): control (LO), fed milk replacer (MR) containing E. faecium; a lactulose group (L1) containing additional $1 \%$ lactulose and a second lactulose group (L3) containing 3\% lactulose dry matter. The calves were weighed weekly. After 19 weeks the calves were slaughtered and tissues were collected for histological studies. The average daily live weight gain tended to be higher $(\mathrm{P}<0.1)$ for $L 3(1350 \mathrm{~g} /$ day) than $\mathrm{LO}(1288 \mathrm{~g} /$ day). Compared with $\mathrm{LO}$, a reduction $(P<0.001)$ of ileal villus height due to lactulose treatment of approximately $14 \%$ in group $L 1$ and $20 \%$ in $L 3$ was determined. A significant decrease in the depth of the crypts about $12 \%$ in $L 1$ and $8 \%$ in $L 3$ was detected in the caecum. The surface area of lymph follicles from Peyer's patches was decreased by lactulose treatment. Results show that lactulose has an effect on the morphology of intestine. A significant effect on growth performance can not be confirmed. However, results permit the conclusion that lactulose feeding has the tendency to increase growth performance.
\end{abstract}

Keywords: calves, growth, lactulose, probiotics, villi

\section{Introduction}

A growing area of research is the functional effect of probiotics and prebiotics (Hughes and Rowland, 2001). Probiotics are well defined strains of micro-organisms which beneficially affect the host by improving its intestinal microbial balance (Bezkorovainy, 2001). Increased levels of probiotics in the intestine may be achieved by consumption of dietary substrates (i.e. prebiotics) that are known to stimulate probiotic growth (Mosenthin and Zimmermann, 2000). It has been suggested that a combination of proand prebiotics, the so-called synbiotics, might be more active than the individual components (Roberfroid, 1998). The knowledge that the normal intestinal flora has a protective function against infection provides the basis for the use of probiotics and prebiotics (Gorbach, 2000; McNaught and MacFie, 2001). The application of this know how in veterinary medicine and its versatile use plays an

\footnotetext{
${ }^{\dagger}$ Present address: Weihenstephaner Berg 3, 85354 Freising Germany. E-mail: michael.pfaffl@wzw.tum.de
}

increasingly important role (Vanbelle et al., 1990), in particular when the protective potential of the microbial gut flora is reduced, for example during stress. The vitality and the well being of the animals can be improved and digestive problems and losses caused by nutrition reduced. Prebiotics and probiotics can improve feed conversion and daily weight gain (Krueger et al., 2002; Busch et al., 2004). Various factors like the early separation from their mother, dietary changes or transportation and the contact with a multiplicity of infectious agents could cause the high incidence of intestinal disease in calves. Hence, animals consume less milk (Loerch and Fluharty, 1999), are predisposed to loss of barrier function of the gut (Nabuurs et al., 2001; Soderholm and Perdue, 2001), and may be afflicted with impaired immune function (Sheridan et al., 1994).

Numerous scientists investigated the health-promoting effect of prebiotics like indigestible sugars, e.g. fructooligosaccharides (FOS), inulin and lactulose (Gibson et al., 1995; Kleesen et al., 2001). The positive effects of lactulose 
on colonic metabolism in human, rat, mouse, and pig are well known (Bianchi et al., 1997; Ballongue et al., 1997). In calves, the effect of lactulose on the intestinal morphology is not investigated in detail. The semisynthetic disaccharide lactulose is chemically well characterised and does not occur naturally. Lactulose cannot be digested by mammalian enzymes because of its specific structure (4-ß-D-galactopyranosyl-D-fructose). It is poorly absorbed from the small intestine and is a suitable substrate for some bacteria in the gut, especially in the colon (Schumann, 2002). In vitro investigations demonstrated that lactulose is readily fermented by Bifidobacteria and Lactobacilli, but also by Clostridium perfringens, Escherichia coli and Bacteroides sp. (Smart et al., 1993). These bacteria counteract detrimental species such as Clostridia or Salmonellae (Schumann, 2002) which are, like other pathogenic bacteria, not able to digested lactulose (Johnson, 2001).

The objective of this investigation is to determine the influence and effect of a long-term daily lactulose application on the growth performance and the intestinal morphology in growing calves. In addition the influence of two different lactulose concentrations has been investigated. Thus, we have performed histomorphometrical measurements from the small and large intestine to monitor effects on the morphology of the gastro-intestinal tract (GIT) in pre-ruminant calves.

\section{Material and methods}

Animals, husbandry, feeding and experimental procedures Simmental calves were bred at various farms and directly bought from the Simmental breeding organisation (Zuchtverband für oberbayerisches Alpenfleckvieh e.V.) in Miesbach, Germany. The calves were single-born and immediately separated from their mothers after birth. Calves received post-partum colostrum for 1 week directly from their mother cows, as recommended by the breeding organisation. Afterwards until start of the experimental feeding trial, the calves were fed with milk replacer (MR). The 42 calves were divided in three homogenous experimental groups (no. $=14$ per group, each $50 \%$ male and $50 \%$ female) with balanced weight $(74.4( \pm 2.1) \mathrm{kg})$ and age (39.0 \pm 2.5 days), whereas the females were slightly heavier than males. Animals were housed at the experimental station Karolinenfeld (Bayerische Landesanstalt für Landwirtschaft - LfL, Institut für Tierernährung und Futterwirtschaft) in two segmented pens, half on straw and half on solid floor.

During the feeding experiment, all calves were fed with MR from Milkibeef Top (Milkivit, Trouw Nutrition, Burgheim, Germany) with following composition: $50.2 \%$ skimmed milk, $22.5 \%$ crude protein (CP), $19.5 \%$ crude fat and $10^{9}$ colony forming units (c.f.u.) Enterococcus faecium per kg. All calves had free group access to fresh water and $0.5 \mathrm{~kg}$ hay per day. Feeding group L0 served as control. The other two groups were fed with MR enriched by $1 \%$ (L1) and 3\% (L3) dry matter (DM) lactulose (Lactusat, Milei $\mathrm{GmbH}$, Germany). Contents of Lactusat are shown in Table 1, as stated by the manufacturer (Milei). In order to assure the accuracy of the lactulose concentration in the feeding groups L1 and L3 the MR was mixed with 2.5\% Lactusat for group L1 and 7.5\% Lactusat for group L3. It was exchanged against whey powder to guarantee balanced feeding regimens (Table 2). DM, crude ash, crude fat, starch, $\mathrm{CP}$ and calculated metabolisable energy were formulated to be similar across treatments. Calves of all feeding groups received MR in volumes up to $17.5 \mathrm{l} /$ day in the experimental period of 19 weeks (with corresponding amount of lactulose for L1 and L3), controlled by transponder automatic feeder (Förster Technik, Engen, Germany). The MR was reconstituted in hot water $\left(65^{\circ} \mathrm{C}\right)$ and fed at a temperature of approximately $41^{\circ} \mathrm{C}$. The starting MR concentration at the beginning of the study was $125 \mathrm{~g} / \mathrm{l}$ (week 1), with a continuous and linear increase up to $250 \mathrm{~g} / \mathrm{l}$ at the end of the study (week 19). Calves were weighed every week after feeding, before killing and also the empty body weight was measured. After the dosing period of $133.6 \pm 8.3$ days, animals were slaughtered. The last feeding before slaughtering and tissue sampling was $4 \pm 1 \mathrm{~h}$.

\section{Health status}

The general health status of the calves was monitored by daily physical examination, checking general appearance, animal activity, faeces composition, and time to time rectal temperature. Animals were further inspected by a veterinarian on a weekly basis to confirm identical healthy status of the feeding groups. The experimental procedures followed the current German law on animal production and veterinary inspection (LfL, Grub, Germany).

\section{Histology and histomorphometry of intestinal mucosa}

After slaughtering the GIT was removed and tissue slices of 5 to $7 \mathrm{~mm}$ from the small intestine (middle parts of jejunum and ileum) and large intestine (mid caecum, mid colon) were collected. Immediately after collection, the tissue-samples were washed in physiological $0.9 \% \mathrm{NaCl}$ solution and placed in neutral buffered $10 \%$ formalin (Carl Roth $\mathrm{GmbH}$, Karlsruhe, Germany) for $24 \mathrm{~h}$. The specimen

Table 1 Ingredients of Lactusat (Milei GmbH, Germany)

\begin{tabular}{lclc}
\hline \hline Ingredients & $\%$ & Ingredients & mg per $100 \mathrm{~g}$ \\
\hline Water & 4 & Calcium & 200 \\
Protein & 30 & Potassium & 250 \\
Ash & 1.0 & Sodium & 150 \\
Fat & $<5$ & Magnesium & 30 \\
Lactulose & 42 & Phosphorus & 130 \\
Galactose & 3 & Chloride & 50 \\
Lactose & 7 & pH & 6.4 \\
Epilactose & 2 & & \\
Fructose & $<1$ & & \\
Tagatose & $<1$ & & \\
\hline \hline
\end{tabular}


Table 2 Raw nutrient and energy content of diets (the energy content of the milk replacer was estimated by the feeding programme Zifo (LfL, 2005))

\begin{tabular}{|c|c|c|c|c|c|}
\hline & $\mathrm{LO} n=3$ & $\mathrm{~L} 1 \mathrm{n}=3$ & $\mathrm{~L} 3 \mathrm{n}=3$ & Pooled s.e. & Hay \\
\hline Dry matter (DM, g/kg) & $964 \pm 5$ & $963 \pm 6$ & $963 \pm 6$ & 6 & 854 \\
\hline Raw ash (g/kg DM) & $70 \pm 2$ & $70 \pm 3$ & $68 \pm 2$ & 2 & 52 \\
\hline Crude protein (g/kg DM) & $219 \pm 4$ & $224 \pm 1$ & $234 \pm 5$ & 5 & 124 \\
\hline Crude fat (g/kg DM) & $197 \pm 2$ & $197 \pm 2$ & $196 \pm 1$ & 1 & 16 \\
\hline Crude fibre (g/kg DM) & $0 \pm 0$ & $0 \pm 0$ & $0 \pm 0$ & 0 & 311 \\
\hline Metabolisable energy (MJ/kg DM) & $16.8 \pm 0$ & $16.8 \pm 0$ & $16.9 \pm 0$ & 0 & 9.5 \\
\hline
\end{tabular}

were later trimmed and embedded in paraffin. Thin sections $(7$ to $8 \mu \mathrm{m})$ were cut using the Microtom LEICA RM2145 (Leica, Wetzlar, Germany), mounted on glass slides, and stained with haematoxylin and eosin (HE) and covered with Euktit (Merck, Darmstadt, Germany).

Histological sections were examined with the light microscope Axioskop 2 plus (Zeiss, Oberkochen, Germany) with $10 \times 10.30$ Plan-Neofluar objective connected to the video-based, computer-linked AxioVision 3.1 system that was programmed to perform morphometrical analysis (Blättler et al., 2001). Only for the measurement of the lymph follicle the Stemi $2000-C$ (Zeiss) was used with the $\times 2.5$ objective. Pictures were taken with the AxioCam MRc (Zeiss). The applied objective was changed depend on the examined tissue.

Villus height, crypts depth and for both the width were evaluated on three well orientated villi- and cryptpreparations for each intestinal sampling site. Triplicate measurements for every category (height, depth, width) and section (jejunum, ileum, caecum, colon) were evaluated. Figure 1 illustrates the measurements that were made. Furthermore, the area of at least six lymph follicle in Peyer's patches in the ileum (no. $=84$ per group) were evaluated. For confirming the uninjured mucosa integrity of the collected samples, the following qualitative criteria were controlled: villus fusion, villus atrophy, crypt architectural disruption, disruption or distortion of epithel cells and lymph follicles.

\section{Statistical analysis}

All measurement values are expressed as mean \pm s.e. For group differences, villus heights and width, villus height/ width ratios, crypt depths and width and surface of the lymph follicle of Peyer's patches were analysed with the program of Statistical Packages for the Social Sciences (2003) using two-way ANOVA. In order to find out whether lactulose has different sex-specific effects the pairwise multiple comparison procedures were processed with the Holm-Sidak method. The significance level was set at 0.05 for all tests.

\section{Results}

All calves stayed healthy and no animal losses were registered during the feeding experiment. No medication was applied to the animals during the 19 weeks.

\section{Feed intake and body weight}

The average daily MR intake (Table 3 ) was significant higher in feeding group L3 $(P<0.05)$. An increased intake of CP and energy for group L3 was achieved, due to the feeding of lactulose. Male calves showed a similar average daily MR intake between treatment groups, though the female calves of group L1 $(P<0.05)$ showed a lower average daily MR intake $(P<0.05)$. Growth performance is presented in detail in Table 4. A positive trend on growth
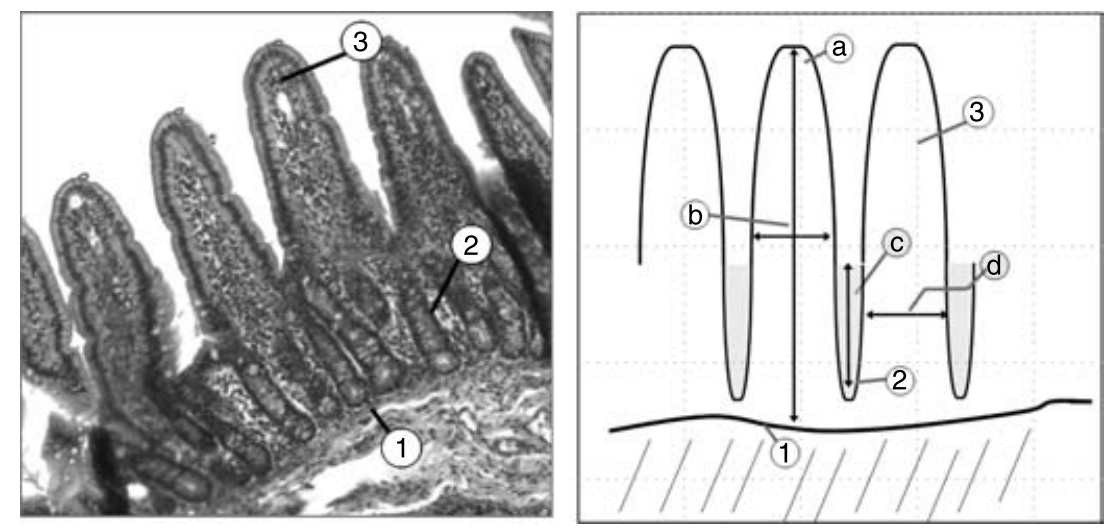

Figure 1 Morphological measurements in the intestine: (1) lamina muscularis mucosae; (2) crypt of Lieberkuhn; (3) villus. Measurements in the small and large intestine were combined pictured in the diagram. Small intestine: (a) villus height (from the tip of the villus to the lamina muscularis mucusae; (b) villus width (distance from villi-junction to the next - perpendicular to the height). Large intestine: (c) depth of crypt (from the tip to the lamina muscularis mucusae - in the large intestine villi is inexistent; (d) width of crypt (perpendicularly to the depth). 
Fleige, Preißinger, Meyer and Pfaffl

Table 3 Average daily food and nutritient intake

\begin{tabular}{|c|c|c|c|c|c|c|c|}
\hline \multirow[b]{2}{*}{ Intake $^{\dagger}$} & \multicolumn{3}{|c|}{ Experimental group } & \multirow[b]{2}{*}{ Pooled s.e. } & \multicolumn{3}{|c|}{ Significance of group differences } \\
\hline & LO & L1 & L3 & & L0 v. L1 & L0 v. L3 & L1 v. L3 \\
\hline \multicolumn{8}{|l|}{ MR intake } \\
\hline MR (g DM) & 2080 & 2019 & 2199 & 45 & & * & ** \\
\hline male & 1958 & 1934 & 2133 & 73 & & & \\
\hline female & 2201 & 2104 & 2264 & 26 & * & & ** \\
\hline Energy (MJ ME) & 35 & 34 & 37 & 1 & & * & $* *$ \\
\hline Crude protein (g) & 455 & 452 & 514 & 10 & & $* * *$ & $* * *$ \\
\hline Ether extract $(\mathrm{g})$ & 410 & 398 & 433 & 9 & & * & $* *$ \\
\hline \multicolumn{8}{|l|}{ Total intake } \\
\hline Hay (g DM) & 205 & 207 & 211 & & & & \\
\hline Total food (kg DM) & 2.3 & 2.2 & 2.4 & & & & \\
\hline Energy (MJ ME) & 37 & 36 & 39 & & & & \\
\hline Crude protein $(\mathrm{g})$ & 477 & 475 & 545 & & & & \\
\hline Crude fibre (g) & 68 & 69 & 70 & & & & \\
\hline Ether extract (g) & 409 & 398 & 437 & & & & \\
\hline
\end{tabular}

${ }^{\dagger}$ The milk replacer (MR) intake data show the mean values \pm s.e. For the total intake, no s.e or significance values could be calculated because hay was offered to entire feeding groups (means are different between treatment groups as shown).

performance could be determined in group L3. Increasing dose of lactulose tended $(P<0.1)$ to increase average daily gain (ADG), especially for male calves. Feed efficiency was highly variable between the animals and not affected by the lactulose treatment.

Villus height and weight in the small intestine and crypts depths and widths in the large intestine

Villus height and width in the jejunum were unchanged in feeding groups (Table 5). However, in the ileum a reduction of villus height with increasing lactulose treatment $(P<0.001)$ was detected, with no change in villus width. In the control group, villus height and width between jejunum and ileum were not significantly different, but in both lactulose groups the villus height was significant lower in ileum than in jejunum (L1: $P<0.01$; L3: $P<0.001$ ). The villus width in the jejunum was decreased because of the $1 \%$ lactulose treatment $(P<0.05)$.

In both treatment groups L1 and L3 the caecal crypt depth was lower $(P<0.001)$ than in the control group. The lactulose treatment effect in L1 group was greater than in L3 $(P<0.05)$. In all groups the crypt depth was significant lower in the colon than in the caecum. There were no treatment effects on crypt width in the caecum, crypt depth and width in the colon and number of lymphatic follicle in the ileum (not shown).

Sex differences in intestinal morphology

In the ileum, the female calves in all feeding groups exhibited higher villus lengths than male calves, but only in group L3 was this difference significant $(P<0.05)$. Among all animals the caecum crypt depth was different between sexes $(P<0.01)$. In all groups the female calves showed lower crypt depths than the male calves. In the treatment groups (L1 and L3) the crypt depths of female calves were lower $(P<0.001)$. Among male animals only male calves of group L1 showed significantly lower crypt depth. The crypt width was lower in female calves of group L3 $(P<0.05)$. Results of the pairwise multiple comparison procedures are not shown.

Histomorphometry of follicles of Peyer's patches in ileum The surface area of lymph follicles from Peyer's patches was decreased by lactulose treatment (Table 5). In the lactulose groups the ileum lymph follicles were smaller than in the control group (L1: $P<0.05 ; \mathrm{L} 3: P<0.01$ ). On closer examination, a significant difference between sexes was apparent $(P<0.001)$. The surface area of female calves in group L0 $(P<0.05)$ and L1 $(P<0.001)$ was larger than in male calves and lower in group L3 $(P<0.01)$. Within the female group the surface areas of lymph follicle in Peyer's patches were smaller in feeding group L3 than in group L0 and L1 whereas the surface area of male calves in feeding group L1 were smaller than in group $L 0$ and $L 3(P<0.01)$.

Table 4 Mortality and adjusted means \pm s.e. of body-weight (BW) gain and feed efficiency of calves fed with milk replacer containing E. faecium (LO) or added with lactulose (L1 and L3) (means are not different $(P>0.05)$ between treatment groups)

\begin{tabular}{lrrrr}
\hline \hline & \multicolumn{3}{c}{ Treatment groups $^{\ddagger}$} & \\
\cline { 2 - 4 } Variable $^{\dagger}$ & \multicolumn{1}{c}{ L0 } & L1 & L3 & Pooled s.e. \\
\hline No of calves & 14 & 14 & 14 & 0 \\
Mortality & 0 & 0 & 0 & 0 \\
Initial BW (kg) & 74 & 74 & 74 & 2 \\
Final BW (kg) & 244 & 245 & 255 & 6 \\
ADG: weeks 1-19 (g/day) & 1288 & 1276 & 1350 & 59 \\
FE & 0.59 & 0.61 & 0.59 & 0.07 \\
\hline \hline
\end{tabular}

${ }^{\dagger} \mathrm{ADG}=$ average daily gain; $\mathrm{FE}=$ feed efficiency, expressed as ADG ( $\mathrm{g} /$ day)/ milk replacer intake ( $\mathrm{g} / \mathrm{day})$.

${ }^{\ddagger}$ Only group difference L1 v. L3 approached significance for ADG $(P<0.1)$. 
Table 5 Mean values for villus areas and heights and crypts depths in jejunum and ileum, size of lymph follicle area in Peyer's patches (ileum) and crypt depths in colon and caecum in calves fed milk replacer (MR) (LO), MR + 1\% lactulose per MR (L1) and MR $+3 \%$ lactulose per MR (L3) (means are different between treatment groups as shown)

\begin{tabular}{|c|c|c|c|c|c|c|c|}
\hline \multirow[b]{2}{*}{ Trait } & \multicolumn{3}{|c|}{ Experimental group } & \multirow[b]{2}{*}{ Pooled s.e. } & \multicolumn{3}{|c|}{ Significance of group differences } \\
\hline & LO & L1 & L3 & & L0 v. L1 & L0 v. L3 & L1 v. L3 \\
\hline \multicolumn{8}{|l|}{ Jejunum } \\
\hline No. & 42 & 36 & 41 & & & & \\
\hline Villus width ( $\mu \mathrm{m})$ & 148 & 142 & 148 & 5 & & & \\
\hline Villus height $(\mu \mathrm{m})$ & 920 & 884 & 979 & 26 & $\neq$ & $\neq$ & $\neq$ \\
\hline Villus height/width ratio ${ }^{\dagger}$ & 6.3 & 6.2 & 6.9 & 0.3 & & & \\
\hline \multicolumn{8}{|l|}{ lleum } \\
\hline No. & 38 & 42 & 42 & & & & \\
\hline Villus width $(\mu \mathrm{m})$ & 157 & 160 & 156 & 5 & & & \\
\hline Villus height $(\mu \mathrm{m})$ & 896 & 770 & 727 & 24 & $* * *$ & $* * *$ & \\
\hline Villus height/width ratio ${ }^{\dagger}$ & 5.7 & 4.9 & 4.7 & 0.3 & & * & \\
\hline \multicolumn{8}{|l|}{ Peyer's patches (lymph follicle) } \\
\hline No. & 83 & 84 & 84 & & & & $* *$ \\
\hline Area $\left(\mu m^{2}\right)$ & 363 & 318 & 303 & 14 & * & ** & $* * *$ \\
\hline Male & 334 & 251 & 330 & 11 & $* *$ & & \\
\hline Female & 391 & 385 & 277 & 11 & & $* * *$ & \\
\hline \multicolumn{8}{|l|}{ Caecum } \\
\hline No. & 42 & 42 & 42 & & & & * \\
\hline Crypts depth ( $\mu \mathrm{m})$ & 586 & 515 & 542 & 10 & $* * *$ & $* * *$ & \\
\hline Crypts width $(\mu \mathrm{m})$ & 30 & 30 & 29 & 1.5 & & & \\
\hline \multicolumn{8}{|l|}{ Colon } \\
\hline No. & 42 & 42 & 41 & & & & \\
\hline Crypts depth ( $\mu \mathrm{m})$ & 507 & 478 & 496 & 12 & & & \\
\hline Crypts width ( $\mu \mathrm{m})$ & 29 & 28 & 27 & 1.5 & & & \\
\hline
\end{tabular}

${ }^{\dagger}$ Values are means no. $=14$ per group.

${ }^{\ddagger}$ Approaching significance $(\mathrm{P}<0.1)$.

\section{Discussion}

\section{Growth performance}

Research on probiotics for cattle has increased in recent years and usually has shown a beneficial effect on the host. In the last 10 years, diverse effects, but not always statistically significant, have been found for feed intake, weight gain, decreased scouring, decreased faecal coliform count and reduced demand for antibiotic treatment (Fuller, 2005). Thus, in all experimental groups, we used a MR containing the probiotic bacteria $E$. faecium to achieve a possible improvement of health. The effect of lactulose as a prebiotic in animal nutrition was reported in studies with pigs (Kien et al., 1999; Krueger et al., 2002) and calves (Schroedl et al., 2003; Landwirtschaftskammer Westfalen Lippe and Universität Leipzig, 2003). However, the effect of lactulose on pre-ruminant calves has not been investigated in detail.

In this study, ADG tended to be higher for L3 than L1 and was numerically higher for L3 than L0. Intake of MR was increased in group L3, so that average daily CP intake was about $13 \%$ higher for $L 3$ than $L 0$. This could represent a direct effect of lactulose on gut morphology or an indirect effect of 3\% lactulose inclusion on sweetness. Quigley et al. (2006) reported that increasing the content of CP in $M R$ increases $A D G$ and efficiency of gain. Other trials in pigs observed no additional benefits from the use of lactulose (Krueger et al., 2002). This is understandable since the initial status of the microbial colonisation of the intestine can differ widely between studies. Furthermore, the extent to which the well being and the performance are improved or maintained also depends on other factors, especially the composition of the diet, the sanitary conditions and the performance level (North Carolina Cooperative Extension, 2005). An accurate and reliable prediction of the lactulose efficacy in calves is not possible at this time.

\section{GIT histology}

As seen in previous studies, within the small intestine villus heights were the greatest in the jejunum (Blättler et al., 2001), possibly due to enhanced differentiation from crypt cells to villus epithelial cells. This gut segment is thought to play a major role in absorption of the digestion products, because the intestinal surface is expected to be positively associated with absorptive capacity (Ganapathy et al., 1994). Based on histomorphological analyses, our study indicates that the feeding of lactulose decreased the villus sizes only in ileum. These results disagree with those obtained by Pelicano et al. (2005), who found no differences in the ileal villus height with the use of prebiotics in broiler chickens. The continual reduction of the villus height in the ileum could be explained by a decreasing cell 
proliferation or/and an increasing apoptosis caused by the feeding of lactulose. Apoptosis is especially relevant in the GIT because it is an important process responsible for maintenance of the cellular balance between proliferation and death and crucial for normal morphology and function (Hall et al., 1994). Prebiotics are proven to increase apoptosis in the intestine in order to exert a protective effect in carcinogenesis (Hughes and Rowland, 2001). Especially lactulose is said to reduce cell proliferation after supplementation for some days (Kien et al., 1999). The synbiotic application of pro- and prebiotica could amplify this effect by reducing the number of aberrant crypts (Kien et al., 2004). Although a higher lactulose concentration in the ileum than in the jejunum might be a reason for the effect on villus heights only in the ileum. In a study with pigs from Kamphues et al. (2003) and Branner et al. (2004) higher lactulose concentrations were measured at the end of the small intestine than in the jejunum. Lactulose concentration in chyme of calves deserves further study.

The decreasing crypt depth in the caecum due to lactulose-supplementation could also be explained by the already mentioned effect of prebiotics to decrease proliferative activity and to increase apoptotic rates. The production of short-chain fatty acids, like butyrate along with acetate and propionate, in the lumen of the hindgut by bacterial fermentation of lactulose was identified in previous work as a reason for this morphological effect (Mandal et al., 2001). A number of different studies (and experimental paradigms) reported lower colonic cell proliferation by increased synthesis of butyric acid (Kien et al., 1999; Klien et al., 2006). In the large intestine this could possibly lead to a shortening of the crypts as was found in our study. In contrast to previous finding, Nilsson and Nyman (2005) and Fernandes et al. (2000) reported that lactulose yielded high proportions of acetic acid and low proportions of butyric acid. In further work analyses of the butyric acid concentration in the chyme should be conducted in calves.

\section{Effect of lactulose on lymph follicles in Peyer's patches} A significant influence of lactulose-supplementation was shown on the gut-associated lymphoid tissue (GALT). In the GALT the Peyer's patches are the main component and especially present in the ileum part of the GIT (Norrman et al., 2003). Ileal Peyer's patches are a primary lymphoid organ and play a major role in the development of B-cells (Norrman et al., 2003). In both treatment groups a smaller size of the lymph follicles was observed with sex-specific differences (L1: $P<0.05$; $L 3: P<0.01$ ) suggesting lower immunological activity throughout the lactulose rich feeding. The lymph follicles of male calves were only significantly affected in group L1. In contrast, only the female calves from group L3 with the highest lactulose feeding showed a significant dependence. The lymph follicle decreased significantly in the supplemented group $(P<0.01)$, which is explained by the stabilisation of the intestinal environment by the reduction of pathogen bacteria which leads to a reduced activation of the immune system. In this way the necessity of the host's immune system to react against harmful bacteria is decreased and this could lead to a reduced surface of lymphatic follicle in the intestine. Further analyses are necessary to confirm this assertion about the effect of lactulose on the Peyer's patches.

\section{Conclusion}

This study indicates that lactulose feeding in combination with $E$. faecium affects the morphology of the small and large intestine in pre-ruminant calves. GALT activation was reduced via the Peyer's patches in the ileum. Inclusion of $1 \%$ lactulose did not affect growth performance, but ADG tended to increase when lactulose inclusion was 3\%. The effects of lactulose are obviously sex-specific: male calves tended to have higher body weight and female calves tended to have more changes in intestinal morphology in response to lactulose. Further studies are required to test the interaction between lactulose and probiotics such as E. faecium.

\section{Acknowledgements}

The research was supported by the $\mathrm{H}$. Wilhelm SchaumannStiftung in Germany. Special thanks are due to the Landesuntersuchungsamt (LUA, Oberschleißheim) in Germany for their excellent paraffin embedding and many thanks to Milei GmbH providing the Lactusat, and Milkivit, Trouw Nutrition, located in Burgheim, Germany, for preparing the milk replacer.

\section{References}

Ballongue J, Schumann C and Quignon P 1997. Effects of lactulose and lactitol on colonic microflora and enzymatic activity. Scandinavian Journal of Gastroenterology 32, 41-44.

Bezkorovainy A 2001. Probiotics: determinants of survival and growth in the gut. American Journal of Clinical Nutrition 73, 399-405.

Bianchi G, Ronchi M and Marchedini G 1997. Effects of lactulose on carbohydrate metabolism and diabetes mellitus. Scandinavian Journal of Gastroenterology 32, 62-64.

Blättler U, Hammon JM, Morel C, Philipona C, Rauprich A, Romé V, Le Huërou-Luron I, Guilloteau P and Blum JW 2001. Feeding colostrum, its composition and feeding duration variably modify proliferation and morphology of the intestine and digestive enzyme activities of neonatal calves. Journal of Nutrition 131, 1256-1263.

Branner GR, Böhmer BM, Erhardt W, Henke J and Roth-Maier DA 2004. Investigation on the precaecal and faecal digestibility of lactulose and inulin and their influence on nutrient digestibility and microbial characteristics. Archives of Animal Nutrition 58, 353-366.

Busch A, Hermann HH, Kühn I, Simon O, Struck J and Süphke E 2004. Probiotics in animal nutrition. Arbeitsgemeinschaft für Wirkstoffe in der Tierernährung e.V. (AWT). (http://www.awt-feedadditives.de/fileadmin/awt/pdf/ probiotics.pdf)

Fernandes J, Venketeshwer Rao A and Wolever TMS 2000. Different substrates and methane producing status affect short-chain fatty acid profiles produced by in vitro fermentation of human feces. The Journal of Nutrition 130, 1932-1936.

Fuller R 2005. Probiotics, the scientific basis. Chapman and Hall, London.

Ganapathy V, Brandsch M and Leibach FH 1994. Intestinal transport of amino acids and peptides. In Physiology of the gastrointestinal tract, vol. 2 (ed. LR Johnson, DH Alpers, J Christensen, ED Jacobson and JH Walsch), pp. 1773-1794. Raven Press, New York. 
Gibson GR, Beatty ER, Wand X and Cumings JH 1995. Selective stimulation of Bifidobacteria in the human colon by oligofructose and inulin. Gastroenterology 108, 975-982.

Gorbach SL 2000. Probiotics and gastrointestinal health. American Journal of Gastroenterology 95, 2-4.

Hall PA, Coates PJ, Ansari B and Hopwood D 1994. Regulation of cell number in the mammalian gastrointestinal tract: the importance of apoptosis. Journal of Cell Science 107, 3569-3577.

Hughes R and Rowland IR 2001. Stimulation of apoptosis by two prebiotic chicory fructans in the rat colon. Carcinogenesis 22, 43-47.

Johnson S 2001. Clostridial constipation's broad pathology. Medical Hypotheses 56, 532-536.

Kamphues J, Tabeling R and Stuke 0 2003. [Possible interesting dietetic effects of lactulose as a feed additive in pig feed.] Deutsche Tierärztliche Wochenschrift 110, 365-368.

Kien CL, Chang JC, Cooper JR and Frankel WL 2004. Effects of prefeeding a prebiotic on diarrhea and colonic cell proliferation in piglets fed lactulose. Journal of Parenteral and Enteral Nutrition 28, 22-26.

Kien CL, Murray RD, Qualman SJ and Marcon M 1999. Lactulose feeding in piglets: a model for persistent diarrhoea and colitis induced by severe sugar malabsorption. Digestive Disease and Science 44, 1476-1484.

Kleesen B, Hartmann C and Blaut M 2001. Oligofructose and long-chain inulin: influence on the gut microbial ecology of rats associated with human faecal flora. British Journal of Nutrition 80, 1-11.

Klien CL, Schmitz-Brown M, Solley T, Sun D and Frankel WL 2006. Increased colonic luminal synthesis of butyric acid is associated with lowered colonic cell proliferation in piglets. Journal of Nutrition 136, 64-69.

Krueger M, Schroedl W, Isik K, Lange W and Hagemann L 2002. Effects of lactulose on the intestinal microflora of periparturient sows and their piglets. European Journal of Nutrition 41, 26-31.

Landwirtschaftskammer Westfalen Lippe and Universität Leipzig 2003. [Lactulose - an method for resolution during gastro-intestinal disease in animals for production.] Symposium, 29 January, Münster, Germany.

Loerch SC and Fluharty FL 1999. Physiological changes and digestive capabilities of newly received feedlot cattle. Journal of Animal Science 77, 1113-1119.

McNaught CE and MacFie J 2001. Probiotics in clinical practice: a critical review of the evidence. Nutrition Research 21, 343-353.

Mandal M, Olson DJ, Sharma T, Vadlamudi RK and Kumar R 2001. Butyric acid induces apoptosis by up-regulating Bax expression via stimulation of the c- Jun N-terminal kinase/activation protein-1 pathway in human colon cancer cells. Gastroenterology 120, 71-78.
Mosenthin R and Zimmermann B 2000. Probiotics and prebiotics in pig nutrition - alternatives for antibiotics? In Selected topics in animal nutrition. (ed. R Mosenthin). pp. 29-50 Biochemistry and Physiology, University of Alberta, Edmonton, Alberta, Canada.

Nabuurs MJ, Van Essen GJ, Nabuurs P, Niewold TA and Van der Meulen J 2001. Thirty minutes transport causes small intestinal acidosis in pigs. Research in Veterinary Science 70, 123-127.

Nilsson U and Nyman M 2005. Short-chain fatty acid formation in the hindgut of rats fed oligosaccharides varying in monomeric composition, degree of polymerisation and solubility. British Journal of Nutrition 94, 705-713.

Norrman J, David CW, Sauter SN, Hammon HM and Blum JW 2003. Effects of dexamethasone on lymphoid tissue in the gut and thymus of neonatal calves fed with colostrum or milk replacer. Journal of Animal Science 81, 2322-2332.

North Carolina Cooperative Extension 2005. Searching for alternatives to antibiotic growth promoters. North Carolina State University, USA.

Quigley J-D, Wolfe TA and Elsasser TH 2006. Effects of additional milk replacer feeding on calf health, growth, and selected blood metabolites in calves. Journal of Dairy Science 89, 207-216.

Pelicano ERL, Souza PA, Souza HBA, Figueiredo DF, Boiago MM, Carvalho SR and Bordan VF 2005. Intestinal mucosa development in broiler chickens fed natural growth promoters. Brazilian Journal of Poultry Science 7, 221-229.

Roberfroid MB 1998. Prebiotics and synbiotics: concept and nutritional properties. British Journal of Nutrition 80, 197-202.

Schroedl W, Jaekel L and Krueger M 2003. C-reactive protein and antibacterial activity in blood plasma of colostrom-fed calves and the effect of lactulose. Journal of Dairy Science 86, 3313-3320.

Schumann C 2002. Medical, nutritional and technological properties of lactulose. An update. European Journal of Nutrition 41, 117-125.

Sheridan JF, Dobbs C, Brown D and Zwilling B 1994. Psychoneuroimmunology: stress effects on pathogenesis and immunity during infection. Clinical Microbiology Reviews 7, 200-212.

Smart JB, Pillidge CJ and Garman JH 1993. Growth of lactic acid bacteria and bifidobacteria on lactose and lactose-related mono-, di- and trisaccharides and correlation with distribution of beta-galactosidase and phospho-betagalactosidase. Journal of Dairy Research 60, 557-568.

Soderholm JD and Perdue MH 2001. Stress and the gastrointestinal tract II. Stress and intestinal barrier function. American Journal of Physiology. Gastrointestinal and Liver Physiology 280, G7-G13.

Statistical Packages for the Social Sciences 2003. Sigma Stat 3.0. SPSS Inc., Chicago, IL.

Vanbelle $M$, Teller E and Focant M 1990. Probiotics in animal nutrition: a review. Archiv für Tierernährung 40, 543-567. 